\title{
Evolutionary Computing Techniques for Resolving Load Dispatch Problem
}

\author{
Dr. Jennifer S. Raj, \\ Professor, \\ Department of ECE, \\ Gnanamani College of Technology, \\ Namakal, India. \\ Email: jennifer.raj@gmail.com
}

\begin{abstract}
To have an effective scheduling of the generators in order to achieve a perfect planning and functioning of the electric power generation system so as to satisfy the demands required, the economic load dispatch is important. The economic load dispatch is very essential in the network operations in the market with the derestricted electricity and takes a vital role in the power plant operations. ELD problem scopes to meet the load demands fulfilling the various constraints in the operation and minimizing the cost of the operations. The conventional methods put forth to find the solution were found unsuitable as the cost curves of the units were assume to be uneventfully increasing linear functions and whereas the practical systems are nonlinear. So the evolutionary computing engaging the GA in combination with the PSO to resolve the economic load dispatching problem
\end{abstract}

Keywords: Load Dispatching Problem, Cost Optimization, Evolutionary Computing, Genetic Algorithm and Particle Swarm Optimization

\section{Introduction}

The continuous change in the activities of the humans has also increased the load demands of the consumers in the electric power system. Achieving cost-effective electricity production still remains as a challenging and tedious work in the sector of power generation, due to the restrictions and the differing attributes of the resources. Maintaining the quality of supply for the customers involves very high efforts as the customer demands incorporates, the quality, reliability and the availability as well as affordable cost. Since the electric energy is capable of being stored to meet the demands under various scenarios it is required to commit enough number of units for generating power in order to meet the demands in the real time.

The load dispatch is an essential problem that has to be solved to have a power system operation that is economic. This is termed as the economic load dispatch, it defines the level of production in every plant in order to bring down the fuel cost that is required for a particular load that is scheduled otherwise it is defined as the method that allocates the level of generation to the units fixed for generating, such that the load of

ISSN: 2582-2640 (online) 
Journal of Soft Computing Paradigm (JSCP) (2020)

Vol.02/ No. 01

Pages: 47-56

http://irojournals.com/jscp/

DOI: https://doi.org/10.36548/jscp.2020.1.005

the system is delivered in a more economical way. In case of the system with interconnections reducing the cost become an essential requirement. The goal of load dispatch that is economical is to limit the overall value of generation. The procedure followed to a have a load dispatch that is economical for generating devices at exclusive loads should have total gas price at the minimal factor.

In a normal energy gadget, more than one turbines are applied to provide sufficient general output to fulfill a given overall consumer call for. Every of those producing stations can, and typically does, have specific cost-according to-hour feature for its output working variety. A station has a progressing prices for gasoline generation as well as storage ; the cost that are fixed by the station could be more substantial for the nuclear based power plants, as an instance things get highly intricate when utilities make an effort to account for the losses encountered in the transmission line, periodic changes encountered in the hydroelectric plants.

The several standard strategies that were so far put into use as solution to the load dispatching problem were, lambda iteration, approximate Newton Raphson, Lagrange multiplier and the Newton Raphson. These standard strategies were not much convincing as the faced difficulties when in economically dispatch the loads when the load demands changed simultaneously. So every time the load changes it becomes necessary to compute the economic load dispatch for every loops of computation. It is the computational course where the total demands in generation is distributed across the units involved in producing, by means of reducing the criteria of cost selected and focuses it to the constraint in the operation and the load as well. The block diagram below shows the portion of economic load dispatch in the power control activities.

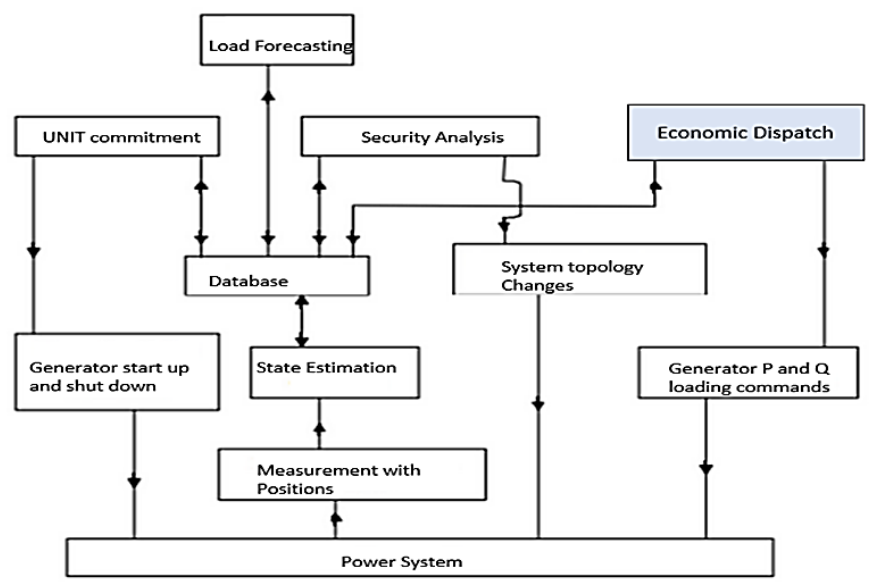

Figure.1 Power System Activities [1]

ISSN: 2582-2640 (online) 
Journal of Soft Computing Paradigm (JSCP) (2020)

Vol.02/ No. 01

Pages: 47-56

http://irojournals.com/jscp/

DOI: https://doi.org/10.36548/jscp.2020.1.005

To provide high reliable solutions to the problem of the economic load dispatch the method proposed in the paper incorporates the GA with the PSO to schedule the requirement accordingly to achieve an economically efficient load dispatch, the following section explain the related work.2 the proposed evolutionary technique as solution to the problem faced in dispatching the loads in 3 , the performance evaluation of the proposed system over two differing systems one with the 5-units and one with 10-units in 4 , and conclusion in 5 followed by the references.

\subsection{Research Problem}

The main goal of the dispatching the load economically is to bring down the cost of the fuels in the power system in order to attain an optimal production across the power plants as well as fulfill the equality as well as the inequality restraints. The fuel cost curve assigned for any unit is approximated as shown in the equation 1 below.

$$
T F_{\text {cost }}=\sum_{x=1}^{n} F\left(\text { Pow }_{x}\right)=\sum_{x=1}^{n} l_{x} \text { pow }_{x}^{2}+m_{x} \text { pow } w_{x}+p_{x}
$$

Where the $T F_{\text {cost }}$ is the total cost of the fuel consumed in generation of power per hour, the coefficient related to the cost consumed in the generator ' $\mathrm{x}$ ' is denoted as the $l_{x}, m_{x}, p_{x}$ and the power generated by generator ' $\mathrm{x}$ ' is denoted as pow $_{x}$, and ' $\mathrm{n}$ ' represents the number of units engaged for generating power. Some of the necessary terms to be considered while planning an economical dispatching methodology are the active power balance equation that provides the actual demand as shown in equation 2.

$$
D_{\text {pow }}=\sum_{x=1}^{n} \text { Pow }_{x}-\text { loss }_{\text {pow }}
$$

Where the $D_{\text {pow }}$ is the demanded power and the loss $_{\text {pow }}$ is the loss incurred while transmitting, and estimated employing the $b$ matrix technique. The next essential terms are the (i) minimum- maximum power limits, the power generated by each unit should fall within the minimum $\left(\operatorname{Min}_{\text {pow }}\right)$ and the maximum $\left(\operatorname{Max}_{\text {pow }}\right.$ ) limit that is set, (ii) ramp rate limits that provides ramp up (present power - previous power) and the ramp down (previous power - present power) constraints and finally the prohibited operating zones (POZ), where the cost curve is found to be discontinues and nonlinear. The POZ for the problems arising in economically dispatching the load is characterized using the upper $\left(U_{P O Z}\right)$ and lower $\left(L_{P O Z}\right)$ boundaries of the POZ.

ISSN: 2582-2640 (online) 
Journal of Soft Computing Paradigm (JSCP) (2020)

Vol.02/ No. 01

Pages: 47-56

http://irojournals.com/jscp/

DOI: https://doi.org/10.36548/jscp.2020.1.005

So the proposed method employs the GA integrated PSO to minimize the cost of the fuel in the power system as shown in the equation 3

$$
\min \sum_{x=1}^{n} F\left(\operatorname{Pow}_{x}\right)
$$

The related works in the next section provides the similar works done to find the solution to the load dispatching problem in the power systems.

\section{Related Works}

Bhattacharya et al [2] proposes the "Biogeography-based optimization for different economic load dispatch problems." Lee et al [3] puts forth the. "Adaptive Hopfield neural networks for economic load dispatch." .Noman, et al [4] proposes "Differential evolution for economic load dispatch problems." Balamurugan, Ret al [5] proposes an "An improved dynamic programming approach to economic power dispatch with generator constraints and transmission losses." Hermanto et al [6] "Soft Computing Technique Based Economic Load Dispatch Using Improved Particle Swarm Optimization."

Sahu, et al [7]. Puts forth the "Economic load dispatch by genetic algorithm in power system." Park, et al [8] proposes the "Economic load dispatch for piecewise quadratic cost function using Hopfield neural network." Panigrahi et al [9]. Proposes the "Bacterial foraging optimisation: Nelder-Mead hybrid algorithm for economic load dispatch." Sivaganesan, D et al [10] puts forth the "Efficient Routing Protocol with Collision Avoidance in Vehicular Networks." dos Santos Coelho et al [11] elaborates "An improved harmony search algorithm for power economic load dispatch." Mugunthan, S. R et al [12] proposes the "Security and Privacy Preserving of Sensor Data Localization Based on Internet of Things."

Liu et al [13]. Proffers "Economic load dispatch constrained by wind power availability: A here-and-now approach." Smys, S et al [14] in his paper puts forward the "DDOS Attack Detection in Telecommunication Network Using Machine Learning." Mandal et al [15] proposes the "Economic load dispatch using krill herd algorithm."

ISSN: 2582-2640 (online) 
Journal of Soft Computing Paradigm (JSCP) (2020)

Vol.02/ No. 01

Pages: 47-56

http://irojournals.com/jscp/

DOI: https://doi.org/10.36548/jscp.2020.1.005

\section{Overview of Genetic Algorithm and Particle Swarm Optimization}

Genetic algorithm: Genetic algorithm following set of rules in short known as GA is a method of searching utilized in processing to identify the proper or approximate solutions to find an optimal solutions for a problem. It is a special class of evolutionary algorithm that is inspired by the evolutionary biology that includes the parameters of the genetic algorithm, it is used in majority of nonlinear approximations, in the proposed method it is used along with the PSO to bring down the cost in the each units. The table.1 below shows the general operations involved in the Genetic Algorithm.

\begin{tabular}{|l|l|}
\hline \multicolumn{1}{|c|}{ Genetic Parameters } & \multicolumn{1}{c|}{ Description } \\
\hline Initialization & $\begin{array}{c}\{ \\
100,000,001,010,011,111,101,110\}\end{array}$ \\
\hline Selection & $\begin{array}{l}\text { Parent A }: 110,100 \\
\text { Parent B: 011,101 }\end{array}$ \\
\hline Cross over & $\begin{array}{l}\text { Child A }: 110,101 \\
\text { Child B : 011, 100 }\end{array}$ \\
\hline Mutation & $\begin{array}{l}\text { Child A } 110101 \\
\text { New Child A : 111110 }\end{array}$ \\
\hline Evaluation & Checks fitness \\
\hline
\end{tabular}

Table.1 General Genetic operations

Particle Swarm Optimization: This evolutionary computing method relies on the social behavior metaphor, it considers a possible solution to a problem as a bird without consistency and distance, which is called an object, moving through a D-dimensional space by changing the location in the space of search based on the experience of the bird and its neighboring birds. In every step of iteration the new velocity is estimated and the position is updated, the best position in each iteration is termed as the pbest after each iterations the

ISSN: 2582-2640 (online) 
Journal of Soft Computing Paradigm (JSCP) (2020)

Vol.02/ No. 01

Pages: 47-56

http://irojournals.com/jscp/

DOI: https://doi.org/10.36548/jscp.2020.1.005

positions are prioritized based on their velocity, and finally the gbest is estimated, it is the best position obtained at the end of all iterations the equation 4 below is framed accordingly.

$$
\begin{aligned}
& \text { velocity }_{\text {update }}=\text { inertia }_{\text {factor }} * \text { pres }_{\text {velocity }}+a_{1} * P R_{1}\left(\text { pbest }- \text { pres }_{\text {position }}\right)+a_{2} * \\
& P R_{2}(\text { gbest }- \text { pres } \\
& \text { position })
\end{aligned}
$$

Where ' $a$ ' and the 'PR' represents the acceleration and the positive random number respectively and the inertia factor is given taking into consideration the maximum $(M I F)$ and the minimum $(m I F)$ inertia factors, the maximum number of iterations $\left(\max _{i t}\right)$ and the number of the particles as shown in equations 5

$$
\text { inertia }_{\text {factor }}=M I F-\left(\frac{M I F-m I F}{\max _{i t}}\right) * \text { Number of iterations }
$$

This method of alteration in the position of the particle is happens until the criteria for the stopping or the optimal solution is achieved.

\subsection{Proposed Hybridized GA-PSO}

The proposed procedure combines the natural evolution process of the GA and the social discerning capability PSO to have proper scheduling that is cost efficient, the evolutionary process, followed the estimation of the updated velocity is done in the paper, to efficiently minimize or optimize the expense in the power system while dispatching the load according to the demands. The algorithm below provide the step wise description of the proposed Hybridized GA-PSO

Step .i. The algorithm begins with the initialization of the population,

Step ii. The population selected are evaluated according to their fitness and the process is terminated if found with the fittest.

Step iii. The fittest parent (equal incremental cost and normalized cost) is selected. Where the relationship across the equal incremental cost and normalized cost is given as $C_{\min }+$ normalized cost $\left(C_{\max }-\right.$ $C_{\min }$ ) where the $C_{\max }, C_{\min }$ is the computed values as shown in equation 6 and 7 below.

ISSN: 2582-2640 (online) 
Journal of Soft Computing Paradigm (JSCP) (2020)

Vol.02/ No. 01

Pages: 47-56

http://irojournals.com/jscp/

DOI: https://doi.org/10.36548/jscp.2020.1.005

$$
\begin{gathered}
C_{\text {max }}=\max \left\{\frac{d F\left(\text { Pow }_{x} \max \right)}{d \text { Pow }_{x}}\right\} \\
C_{\text {min }}=\min \left\{\frac{d F\left(\text { Pow }_{x} \text { min }\right)}{d \text { Pow }_{x}}\right\}
\end{gathered}
$$

Step iv. The new offspring's are generated with the non-uniform arithmetic cross over and the non-uniform mutation process.

Step v. The fitness of the generated offspring's are tested applying the equation 8

$$
F_{F}=\frac{1}{1+\frac{1}{\sum F}}
$$

Step vi. If fittest solution found the process is terminate and continued with PSO else move to step iii.

Step vii. Calculates the update velocity based on the equation 4

Step viii. Estimates position update determining the current position, with the previous location and the velocity observed at that instant. Periodically the particle accelerations calculated along with the position and the velocity.

Step ix obtain the pbest and gbest

Step x stop when optimal solution is reached otherwise go to step iii.

\section{Performance Evaluation}

The feasibility as well as the effectiveness of the proposed method put forth to solve the problem found in economically dispatching the loads was validated over dual power system with 5 and 10 units taking into

ISSN: 2582-2640 (online) 
Journal of Soft Computing Paradigm (JSCP) (2020)

Vol.02/ No. 01

Pages: 47-56

http://irojournals.com/jscp/

DOI: https://doi.org/10.36548/jscp.2020.1.005

consideration the loss incurred in the power during transmission, the POZ and the upper and the lower ramp limits

Two power system equipped with the 5 and 10 units employed under the thermal generation, where the total load demanded was assigned to be $1260 \mathrm{MW}$ and $2520 \mathrm{MW}$ respectively, with the Min $_{\text {pow }}$ and the Max $_{\text {pow }}$ limit set between 50 to 500 respectively and the ramp limits ranging between 50 to 100 and POZ ranging as follows [100,130], [310,340], [150,180], [80, 100] [160,190], [120,140] etc. the transmission loss were estimated applying the B matrix. The table .2 and 3 below shows the results observed over the proposed method

\begin{tabular}{|l|l|l|l|l|}
\hline \multicolumn{1}{|c|}{ Unit } & \multicolumn{1}{|c|}{ Standard } & \multicolumn{1}{c|}{ GA } & \multicolumn{1}{c|}{ PSO } & GA PSO \\
\hline 1 & 476.345 & 544.03 & 540.24 & 590.67 \\
\hline 2 & 177.567 & 178.46 & 179.57 & 180.47 \\
\hline 3 & 265.2819 & 278.78 & 275.65 & 290.98 \\
\hline 4 & 136.2723 & 137.17 & 139.09 & 145.50 \\
\hline 5 & 75.123 & 80.34 & 84.47 & 100.45 \\
\hline $\begin{array}{l}\text { Output } \\
\text { Power }\end{array}$ & 1130.590 & 1218.78 & 1219.02 & 1308.07 \\
\hline $\begin{array}{l}\text { COST Of } \\
\text { generation }\end{array}$ & 11.456 & 15.456 & 17.834 & 14.300 \\
\hline $\begin{array}{l}\text { Lossesin } \\
\text { power }\end{array}$ & 15.07 & 13.45 & 12.55 & 11.03 \\
\hline
\end{tabular}

Table.2 Comparison of outputs of 5 units

Results obtained were compared with the conventional methods and the GA and the PSO method and was observed that the proposed method with the hybridized GA-PSO shows improved cost optimization for the load dispatching compared to the other methods.

ISSN: 2582-2640 (online) 
Journal of Soft Computing Paradigm (JSCP) (2020)

Vol.02/ No. 01

Pages: 47-56

http://irojournals.com/jscp/

DOI: https://doi.org/10.36548/jscp.2020.1.005

\begin{tabular}{|l|l|l|l|l|}
\hline \multicolumn{1}{|c|}{ Unit } & \multicolumn{1}{|c|}{ Standard } & \multicolumn{1}{|c|}{ GA } & \multicolumn{1}{|c|}{ PSO } & GA - PSO \\
\hline 1 & 476.345 & 544.03 & 540.24 & 590.67 \\
\hline 2 & 177.567 & 178.46 & 179.57 & 180.47 \\
\hline 4 & 265.2819 & 278.78 & 275.65 & 290.98 \\
\hline 5 & 136.2723 & 137.17 & 139.09 & 145.50 \\
\hline 6 & 75.123 & 80.34 & 84.47 & 100.45 \\
\hline 7 & 70.005 & 76.103 & 75.45 & 89.05 \\
\hline 8 & 60.12 & 61.12 & 63.12 & 79.12 \\
\hline 9 & 45.34 & 47.30 & 55.34 & 65.44 \\
\hline 10 & 34.02 & 44.02 & 48.01 & 54.12 \\
\hline $\begin{array}{l}\text { Output } \\
\text { Power }\end{array}$ & 22.04 & 30.04 & 29.14 & 42.54 \\
\hline $\begin{array}{l}\text { COST of } \\
\text { generation }\end{array}$ & 1362.115 & 1477.36 & 1490.08 & 1638.34 \\
\hline $\begin{array}{l}\text { Losses in } \\
\text { Power }\end{array}$ & 15.07 & 3 & & 16.300 \\
\hline
\end{tabular}

Table.3 - Comparison of outputs of 10 units

\section{Conclusion}

The problem faced in economically dispatch the load demanded in the power system was addressed in the paper employing GA integrated PSO, and considering the POZ, ramp rates and the losses incurred in the transmission, the proposed method was validated over a two power systems with 5 and 10 generating units and was found to provide more convincing results compared to the exiting standard strategies as well as GA and the PSO methods providing a solution that satisfies the constraints.

\section{References}

[1] https://shodhganga.inflibnet.ac.in/bitstream/10603/117969/4/chapter\%202.pdf

[2] Bhattacharya, Aniruddha, and Pranab Kumar Chattopadhyay. "Biogeography-based optimization for different economic load dispatch problems." IEEE transactions on power systems 25, no. 2 (2009): 1064-1077.

ISSN: 2582-2640 (online) 
Journal of Soft Computing Paradigm (JSCP) (2020)

Vol.02/ No. 01

Pages: 47-56

http://irojournals.com/jscp/

DOI: https://doi.org/10.36548/jscp.2020.1.005

[3] Lee, Kwang Y., Arthit Sode-Yome, and June Ho Park. "Adaptive Hopfield neural networks for economic load dispatch." IEEE transactions on power systems 13, no. 2 (1998): 519-526.

[4] .Noman, Nasimul, and Hitoshi Iba. "Differential evolution for economic load dispatch problems." Electric power systems research 78, no. 8 (2008): 1322-1331.

[5] Balamurugan, R., and S. Subramanian. "An improved dynamic programming approach to economic power dispatch with generator constraints and transmission losses." Journal of Electrical Engineering \& Technology 3, no. 3 (2008): 320-330.

[6] Hermanto, Bangbang, Wendhi Yuniarto, Rusman Rusman, and Hardiansyah Hardiansyah. "Soft Computing Technique Based Economic Load Dispatch Using Improved Particle Swarm Optimization."

[7] Hermanto, Bangbang, Wendhi Yuniarto, Rusman Rusman, and Hardiansyah Hardiansyah. "Soft Computing Technique Based Economic Load Dispatch Using Improved Particle Swarm Optimization."

[8] .Sahu, Gajendra, and Kuldeep Swarnkar. "Economic load dispatch by genetic algorithm in power system." International Journal of Science, Engineering and Technology Research (IJSETR) 3, no. 8 (2014).

[9] Park, J. H., Y. S. Kim, I. K. Eom, and K. Y. Lee. "Economic load dispatch for piecewise quadratic cost function using Hopfield neural network." IEEE transactions on power systems 8, no. 3 (1993): 1030-1038.

[10] Panigrahi, B. K., and V. Ravikumar Pandi. "Bacterial foraging optimisation: Nelder-Mead hybrid algorithm for economic load dispatch." IET generation, transmission \& distribution 2, no. 4 (2008): 556-565.

[11] Sivaganesan, D. "EFFICIENT ROUTING PROTOCOL WITH COLLISION AVOIDANCE IN VEHICULAR NETWORKS." Journal of Ubiquitous Computing and Communication Technologies (UCCT) 1, no. 02 (2019): 76-86.

[12] dos Santos Coelho, Leandro, and Viviana Cocco Mariani. "An improved harmony search algorithm for power economic load dispatch." Energy Conversion and Management 50, no. 10 (2009): 2522-2526.

[13] Mugunthan, S. R. "SECURITY AND PRIVACY PRESERVING OF SENSOR DATA LOCALIZATION BASED ON INTERNET OF THINGS." Journal of ISMAC 1, no. 02 (2019): 81-91.

[14] Liu, Xian, and Wilsun Xu. "Economic load dispatch constrained by wind power availability: A here-and-now approach." IEEE Transactions on sustainable energy 1, no. 1 (2010): 2-9.

[15] Smys, S. "DDOS ATTACK DETECTION IN TELECOMMUNICATION NETWORK USING MACHINE LEARNING." Journal of Ubiquitous Computing and Communication Technologies (UCCT) 1, no. 01 (2019): 33-44.

[16] Mandal, Barun, Provas Kumar Roy, and Sanjoy Mandal. "Economic load dispatch using krill herd algorithm." International journal of electrical power \& energy systems 57 (2014): 1-10. 